\title{
Role of miR-647 in human gastric cancer suppression
}

\author{
WENLONG CAO $^{1 *}$, WEIYUAN WEI ${ }^{1 *}$, ZEXU ZHAN $^{1}$, DONGYI XIE $^{1}$, YUBO XIE $^{2}$ and QIANG XIAO \\ Departments of ${ }^{1}$ Surgery and ${ }^{2}$ Anaesthesiology, The First Affiliated Hospital of Guangxi Medical University, \\ Nanning, Guangxi Zhuang Autonomous Region 530021, P.R. China
}

Received July 6, 2016; Accepted January 3, 2017

DOI: 10.3892/or.2017.5383

\begin{abstract}
MicroRNAs (miRNAs) regulate various oncogenes concomitantly, resulting in tumor suppression. They regulate proliferation and migration pathways in tumor development, suggesting a potential therapeutic role. In the present study, we found that miR-647 was markedly downregulated in gastric cancer (GC), and was significantly correlated with reduced tumor size and metastasis. In addition, miR-647 was also reduced in GC cell lines. Furthermore, overexpression of miR-647 in the GC cell lines inhibited cell proliferation, promoted cell cycle arrest at the G0/G1 phase and induced cell apoptosis. miR-647 also significantly inhibited tumor growth in vivo. Notably, we found that miR-647 overexpression suppressed the migration and invasion of the cancer cells, particularly liver metastasis in nude mice. miR-647 also reduced the expression levels of genes associated with proliferation and metastasis in tumors, including $A N K 2, F A K$, MMP2, MMP12, CD44 and SNAIL1. Overall, our findings demonstrated that miR-647 exerts powerful antitumorigenic effects in vitro and in vivo, and may represent a promising therapeutic agent against GC.
\end{abstract}

\section{Introduction}

Globally, gastric cancer (GC) is one of the most common malignancies of the digestive tract with a 5-year patient survival rate of less than $25 \%$, and represents the second leading cause of cancer-related deaths worldwide $(1,2)$. Tumor growth and metastasis of GC are major causes of increased

Correspondence to: Professor Qiang Xiao, Department of Surgery, The First Affiliated Hospital of Guangxi Medical University, 6 Shuang-yong Road, Nanning, Guangxi Zhuang Autonomous Region 530021, P.R. China

E-mail: xiaoqiang20050@aliyun.com

Professor Yubo Xie, Department of Anaesthesiology, The First Affiliated Hospital of Guangxi Medical University, 6 Shuang-yong Road, Nanning, Guangxi Zhuang Autonomous Region 530021, P.R. China

E-mail: xieyubo715001@aliyun.com

*Contributed equally

Key words: miR-647, gastric carcinoma, proliferation, metastasis mortality. Unfortunately, due to the absence of biomarkers for early detection, most patients are often diagnosed in advanced stages of metastasis (3). Despite identification of the molecular mechanisms, the pathophysiology of GC remains largely obscure. Therefore, investigation of the regulatory mechanisms underlying the suppression of proliferation and metastasis of GC cells holds the key to effective diagnosis and treatment of GC.

MicroRNAs (miRNAs) regulate multiple genes and target pathways in several human diseases, including cancer, and therefore, represent potential therapeutic targets (4-6). miRNAs are endogenous small non-coding RNAs consisting of 19-24 nucleotides, each. They regulate gene expression by targeting the 3'-untranslated region of cancer-related mRNAs and function as a 'fine-tuner' in the most important biological processes, including proliferation, apoptosis, invasion and metastasis (7-9). These miRNAs have been shown to modulate pathways involved in GC cell proliferation and metastasis $(10,11)$. Nevertheless, further investigation into the molecular mechanisms of miRNAs in GC is essential for early diagnosis or effective therapeutic intervention. Noteworthy, Rawlings-Goss et al found that miR-647 is associated with the most extensive cancers and may serve as a biomarker for GC (12). A recent study also reported that overexpression of miR-647 was associated with a better prognosis of Taxolresistant ovarian cancer (13). However, the underlying role of miR-647 in GC remains indeterminate.

In the present study, miR-647 was found to play a tumorsuppressor role since inhibition of miR-647 expression in GC was strongly associated with tumor size and metastasis. Overexpression of miR-647 in GC cell lines in vitro and in vivo, inhibited proliferation and metastasis of GC via transcriptional regulation of genes including $A N K 2, F A K, M M P 2$, MMP12, CD44 and SNAIL1.

\section{Materials and methods}

Cell lines and clinical samples. Human GC samples and their corresponding adjacent non-tumor gastric tissues (located $\sim 5 \mathrm{~cm}$ away from the tumor) were collected during surgical resection at The First Affiliated Hospital of Guangxi Medical University (Nanning, China) from 2013 to 2015. All samples were immediately frozen on dry ice and preserved in liquid nitrogen. All the patients provided written informed consent. The present study was approved by the Ethics Committee of The First Affiliated Hospital of Guangxi Medical University. 
Four human GC cell lines (HGC-27, AGS, SGC-7901 and MGC-803) as well as immortalized gastric epithelial GES-1 cells were obtained from the Cell Bank of the Chinese Academy of Sciences (Shanghai, China). Cells were cultured in RPMI-1640 medium (GE Healthcare Life Sciences, South Logan, UT, USA) supplemented with $50 \mathrm{mg} / \mathrm{ml}$ penicillin, $100 \mathrm{mg} / \mathrm{ml}$ streptomycin, and $10 \%$ fetal bovine serum (FBS) at $37.8^{\circ} \mathrm{C}$ and $5.0 \% \mathrm{CO}_{2}$.

$R N A$ extraction and quantitative reverse transcription real-time polymerase chain reaction ( $q R T-P C R)$. RNAs were extracted from tissue samples and cells using TRIzol (Invitrogen Corporation, Carlsbad, CA, USA). The cDNA was synthesized from 1,000 ng RNA samples using PrimeScript ${ }^{\mathrm{TM}}$ RT reagent kit (Takara Bio, Inc., Tokyo, Japan). SYBR ${ }^{\circledR}$ Premix Ex Taq $^{\mathrm{TM}}$ II (Tli RNaseH Plus) and a ROX Plus reagent kit (Takara Bio, Inc.) were used to amplify mRNA or miRNA expression with GAPDH (mRNA) or U6 (miRNA) as internal standards. The mRNA and miRNA expression was analyzed using the $2^{-\Delta \Delta \mathrm{Ct}}$ method. All primer sequences are listed in Table I.

Cell invasion assay. The Transwell insert was coated with $75 \mu \mathrm{l}(1 \mu \mathrm{g} / \mathrm{ml}$ ) Matrigel (BD Biosciences, Mountain View, CA, USA) and 5.0x10 cells in $200 \mu \mathrm{l}$ serum-free media were transferred to the upper chamber $(6.5 \mathrm{~mm}$; Corning, New York, NY, USA). The lower compartment was filled with $700 \mu 1$ medium containing 5\% FBS as a chemoattractant. After culturing for $24 \mathrm{~h}$, the cells in the lower chamber were stained with Giemsa and the migrating cells were counted under a microscope from 8 randomly selected fields (magnification, $\mathrm{x} 200$ ).

Transfection. The miR-647 mimic and the null vector LV-GFP were purchased from GeneChem (Shanghai, China). Cells were infected with the lentiviral vector at $25 \mathrm{PFU} / \mathrm{cell}$ (SGC7901) or $60 \mathrm{PFU} / \mathrm{cell}$ (MGC-803) [multiplicity of infection (MOI), 25 or 60] at a cell confluency of 35\%. Six groups of cells were identified as follows. Cells in the 7901-Ctrl (or 803-Ctrl) represent SGC-7901 (or MGC-803) cells without any treatment. Cells in the 7901-NC (or 803-NC) group were SGC-7901 (or MGC-803) cells transfected with the negative control lentiviral vector LV-GFP, and cells in the 7901-647 (or 803-647) group were SGC-7901 (or MGC-803) cells transfected with the recombinant lentivirus vector miR-647 mimic. After $24 \mathrm{~h}$ of transfection, the cells were cultured under normal conditions. The cells were then harvested and used.

Cell proliferation assay. Cell proliferation was assessed using the Cell Counting Kit-8 (CCK-8; Dojindo, Kumamoto, Japan). Cells in each group were transferred into 96 -well plates at a density of $1.5 \times 10^{3} /$ well and incubated at $37^{\circ} \mathrm{C}$ and $5 \% \mathrm{CO}_{2}$ for $24,48,72$ or $96 \mathrm{~h}$ followed by the addition of $10 \mu \mathrm{l}$ of CCK- 8 reagent into each well and incubation at $37^{\circ} \mathrm{C}$ for $4 \mathrm{~h}$. The absorbance was read at $450 \mathrm{~nm}$ using a microplate reader.

Cell cycle assay. Flow cytometry was performed to analyze the cell cycle in $1 \times 10^{6}$ trypsinized cells, fixed with $70 \%$ ethanol and stored at $4^{\circ} \mathrm{C}$ for $12 \mathrm{~h}$. The cells were incubated in a $100 \mu \mathrm{l}$ solution containing $200 \mathrm{ng} / \mathrm{ml} \mathrm{RNase}$ at $37^{\circ} \mathrm{C}$ for $30 \mathrm{~min}$. Propidium iodide (PI) $(400 \mu \mathrm{l})$ was added. The cells were
Table I. Sequences of theprimers for quantitative reverse transcriptase real-time polymerase chain reaction.

\begin{tabular}{lll}
\hline Gene & & \multicolumn{1}{c}{ Primer sequences } \\
\hline miR-647 & (F) & 5'-GUGGCUGCACUCACUUCCUUC-3' \\
miR-647 & (R) & 5'-CTCAACTGGTGTCGTGGA-3' \\
U6 & (F) & 5'-TTATGGGTCCTAGCCTGAC-3' \\
U6 & (R) & 5'-CACTATTGCGGGTCTGC-3' \\
ANK2 & (F) & 5'-CAGCTACATTGTGTGGCATTCTA-3' \\
ANK2 & (R) & 5'-CTACAGTGCAGTGGCCAGAAG-3' \\
ZNF609 & (F) & 5'-TGCCTTTGTACATTCAGGCAAGA-3' \\
ZNF609 & (R) & 5'-AGGCAGCTCAGCAGCAAACTC-3' \\
KNDC1 & (F) & 5'-CTCTCACGGTGCCAATCACAA-3' \\
KNDC1 & (R) & 5'-TGCCACTAGCTGGCTGCTCTAA-3' \\
TRIM4 & (F) & 5'-CAGTGTGCCAGATACCATTGATGA-3' \\
TRIM4 & (R) & 5'-CCTCCATCCAGCAAAGTAGTTCC-3' \\
FAK & (F) & 5'-CAACCACCTGGGCCAGTATTATC-3' \\
FAK & (R) & 5'-CCATAGCAGGCCACATGCTTTA-3' \\
MMP2 & (F) & 5'-CCGTGTTTGCCATCTGTTTTAG-3' \\
MMP2 & (R) & 5'-AGGTTCTCTTGCTGTTTACTTTGGA-3' \\
MMP12 & (F) & 5'-ACGTGGCATTCAGTCCCTGT-3' \\
MMP12 & (R) & 5'-AACACTGGTCTTTGGTCTCTCAGAA-3' \\
CD44 & (F) & 5'-CAGGGCTGGGCTTAGACAGA-3' \\
CD44 & (R) & 5'-CTGGCCAATGATGTTCACAGA-3' \\
SNAIL1 & (F) & 5'-CAGACCCACTCAGATGTCAAGAA-3' \\
SNAIL1 & (R) & 5'-GGGCAGGTATGGAGAGGAAGA-3' \\
GAPDH & (F) & 5'-GCACCGTCAAGGCTGAGAAC-3' \\
GAPDH & (R) & 5'-TGGTGAAGACGCCAGTGGA-3' \\
& &
\end{tabular}

F, forward; R, reverse.

incubated at ambient temperature for $30 \mathrm{~min}$ in the dark. The results were analyzed using flow cytometry (BD Biosciences).

Cell apoptosis assay. An apoptosis detection kit (BD Biosciences) was used to determine the cellular apoptosis by incubating $2 \times 10^{6}$ cells with $100 \mathrm{ml} 1 \mathrm{X}$ binding buffer containing $50 \mu \mathrm{l} / \mathrm{ml}$ Annexin V-PE and $50 \mu \mathrm{l} / \mathrm{ml} 7$-amino-actinomycin D. After incubation at an ambient temperature in the dark for $30 \mathrm{~min}$, an additional $400 \mu \mathrm{1} 1 \mathrm{X}$ binding buffer was added. The results were analyzed by flow cytometry (BD Biosciences).

Transmission electron microscopy (TEM). The ultrastructure of the cells was observed using TEM. The cells were fixed with $2.5 \%$ glutaraldehyde at $4^{\circ} \mathrm{C}$ overnight and post-fixed in $1 \%$ osmium tetroxide for $30 \mathrm{~min}$, dehydrated in a graded series of ethanol baths, and embedded in Epon. Ultrathin sections were stained with uranyl acetate and lead citrate, and observed under a JEM-2000EX transmission electron microscope (Jeol, Tokyo, Japan).

Wound-healing assay. Cell migration was measured by culturing the GC cells in 6-well plates, and a straight line 
scratch wound was created with a $200-\mu 1$ sterile pipette tip once cells attained $100 \%$ confluency. The wound conditions were monitored at 0,24 and $48 \mathrm{~h}$ microscopically and the relative motility was calculated using the following formula: Relative motility $=($ initial distance - a time point distance $) /$ initial distance x $100 \%$.

Animal studies. All animals were provided by the Guangxi Animal Center (Nanning, China), and the animal studies were approved by the Ethics Committee of The First Affiliated Hospital of Guangxi Medical University. In vivo tumor growth was conducted with $2 \times 10^{6} \mathrm{GC}$ cells in each group re-suspended in $100 \mu 1$ of phosphate-buffered saline (PBS; Beyotime Institute of Biotechnology, Shanghai, China) and the cells were subcutaneously inoculated in the armpit region, respectively, of 5- to 6-week-old BALB/c nude mice (8 mice/ group). After 3 days, the tumors increased in size to $\sim 5.0 \mathrm{~mm}$ in diameter. The tumor size was measured every 3 days using a Vernier caliper and calculated by the formula: Tumor volume $=\mathrm{a} \mathrm{x} \mathrm{b}^{2} / 2$ ( $\mathrm{a}$, length diameter; $\mathrm{b}$, width diameter). The relative tumor volume (RTV) was estimated as follows: $\mathrm{RTV}=\mathrm{V}_{\mathrm{t}} / \mathrm{V}_{0}\left(\mathrm{~V}_{0}\right.$, initial tumor volume; $\mathrm{V}_{\mathrm{t}}$, current tumor volume at the time of measurement). Mice were euthanized 21 days after inoculation of the cells. The xenografts were excised and embedded in paraffin for hematoxylin and eosin staining.

To study metastasis in vivo, $8 \times 10^{4}$ cells of each group were re-suspended in $100 \mu \mathrm{l} \mathrm{PBS}$, and intravenously injected into the tail vein of 5- to 6 -week-old $\mathrm{BALB} / \mathrm{c}$ nude mice (10 mice/group). After 36 days, lungs and livers were excised and embedded in paraffin for further histopathological analysis. The number of mice with metastasis was counted.

Microarray analysis and miR-647 target prediction. The microarray data obtained in the present study from cells in the 803-NC and 803-647 groups were deposited in the UniGene database 219 . RNA samples were analyzed by microarray expression profiling using the GeneChip Hybridization Wash and Stain kit (Affymetrix, Santa Clara, CA, USA) according to the manufacturer's instructions. All the raw data were normalized by quantile method and analyzed. Genes upregulated and downregulated $>1.5$-fold in the 803-647 group compared with those in the 803-NC were selected. The target genes of miR-647 were analyzed by TargetScan (http://www.targetscan.org), microRNA.org (http://www.microrna.org/microrna/home.do) and MiRanda (http://www.miranda.com/).

Western blotting. Cell protein lysates were separated by sodium dodecyl sulfate-polyacrylamide gel electrophoresis and transferred to polyvinylidene fluoride (PVDF) membranes. After blocking with $5 \%$ non-fat milk, the membranes were incubated with the primary antibody overnight at $4^{\circ} \mathrm{C}$ and washed with Tris-buffered saline and Tween-20 (TBST). The membranes were incubated with a dilution of infrared-labeled secondary antibody $(1: 10,000)$ for $1 \mathrm{~h}$. After washing twice with TBST, the optical density was quantified using software provided with the Odyssey scanner (LI-COR Biosciences, Lincoln, NE, USA).

Statistical analysis. Data are presented as mean $\pm \mathrm{SE}$ as analyzed by SPSS 13.0 (SPSS, Inc., Chicago, IL, USA), and deemed to
Table II. Correlations between miR-647 expression and clinical characteristics of the gastric cancer patients $(n=70)$.

\begin{tabular}{|c|c|c|c|c|}
\hline \multirow[b]{2}{*}{ Characteristics } & \multirow{2}{*}{$\begin{array}{l}\text { Total } \\
\text { cases }\end{array}$} & \multicolumn{2}{|c|}{$\operatorname{miR}-647$} & \multirow[b]{2}{*}{ P-value } \\
\hline & & High (n) & Low (n) & \\
\hline Age, years & & & & 0.478 \\
\hline$<60$ & 40 & 14 & 26 & \\
\hline$\geq 60$ & 30 & 13 & 17 & \\
\hline Gender & & & & 0.698 \\
\hline Male & 50 & 20 & 30 & \\
\hline Female & 20 & 7 & 13 & \\
\hline Tumor size $(\mathrm{cm})$ & & & & $0.012^{\mathrm{a}}$ \\
\hline$>3$ & 57 & 18 & 39 & \\
\hline$\leq 3$ & 13 & 9 & 4 & \\
\hline TNM staging & & & & $0.007^{\mathrm{a}}$ \\
\hline $\mathrm{I} / \mathrm{II}$ & 30 & 17 & 13 & \\
\hline III/IV & 40 & 10 & 30 & \\
\hline Node metastasis & & & & $0.007^{\mathrm{a}}$ \\
\hline None & 23 & 14 & 9 & \\
\hline Metastasis & 47 & 13 & 34 & \\
\hline Distant metastasis & & & & $0.028^{\mathrm{a}}$ \\
\hline None & 49 & 23 & 26 & \\
\hline Metastasis & 21 & 4 & 17 & \\
\hline Differentiation & & & & 0.797 \\
\hline $\begin{array}{l}\text { Poor or } \\
\text { undifferentiated }\end{array}$ & 48 & 19 & 29 & \\
\hline Moderate or well & 22 & 8 & 14 & \\
\hline
\end{tabular}

TNM, tumor-node-metastasis. ${ }^{\mathrm{a}} \mathrm{P}<0.05$.

have statistical significance at $\mathrm{P}<0.05$ using the Student's t-test, one-way analysis of variance (ANOVA) or $\chi^{2}$ test.

\section{Results}

Downregulation of miR-647 in GC correlates with proliferation and metastasis. To determine the role of miR-647 in the pathogenesis of GC, we investigated the miR-647 levels in GC tissue specimens and the corresponding non-tumor samples of 70 GC patients and 4 GC cell lines using qRT-PCR. As shown in Fig. 1A, compared with the corresponding non-tumor samples, the miR-647 level in the GC tissue specimens was significantly decreased in 43 of 70 patients $(\mathrm{P}<0.05)$. The histogram also demonstrated an average $0.79 \pm 0.09$-fold downregulation of miR-647 in the GC tissue specimens compared with that noted in the non-tumor samples $(\mathrm{P}<0.05$; Fig. 1B). To address the clinical significance of the downregulation of miR-647 in GC, the relationship between miR-647 expression and clinical pathology was determined (Table II). The GC samples were assigned a cut-off point to distinguish tumors with low-level expression of miR-647 from those with highlevel expression of miR-647. Correlation analysis showed that the low-level expression of miR-647 in GC was significantly 

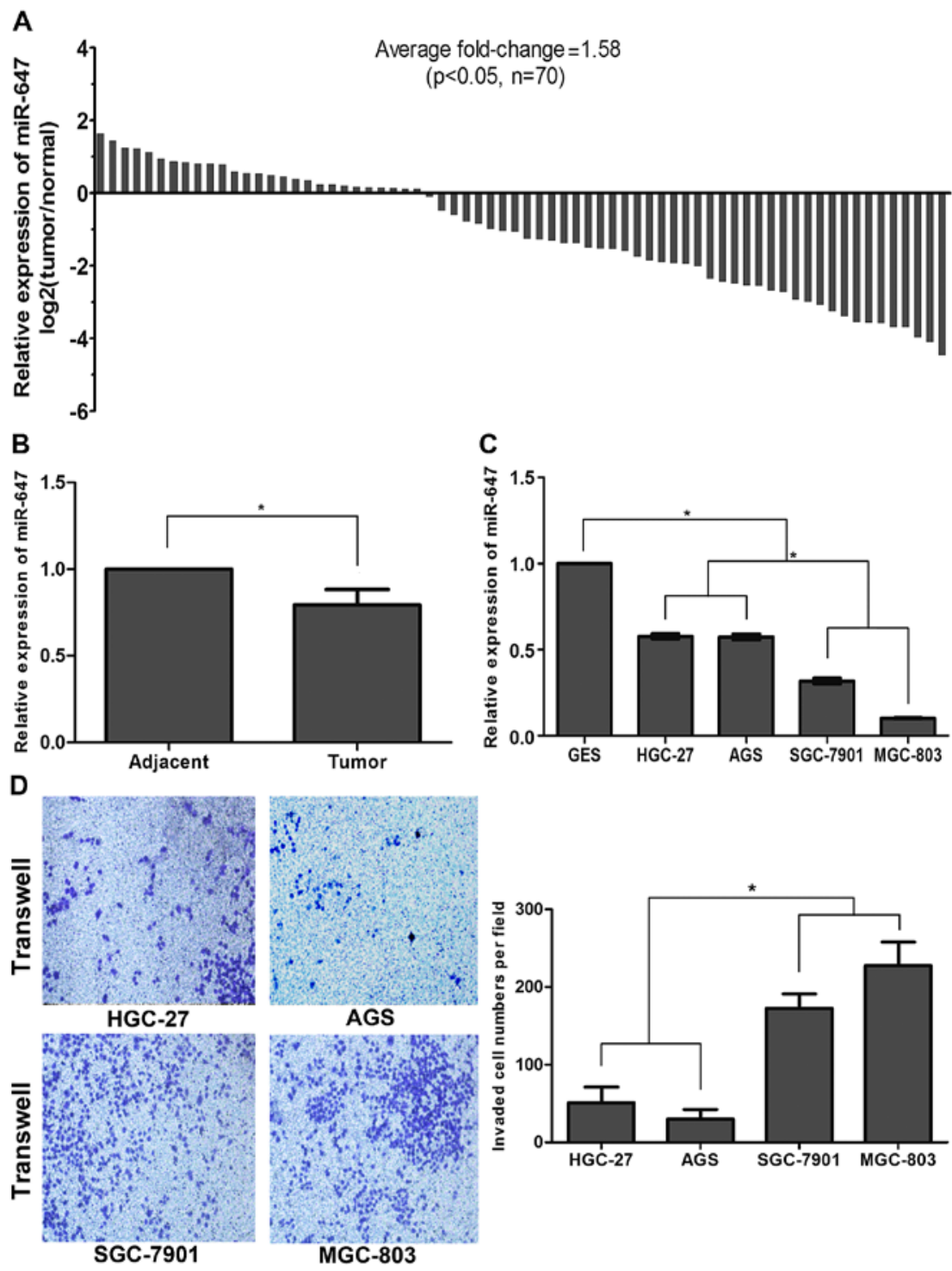

Figure 1. Downregulation of miR-647 in gastric carcinoma (GC) is associated with proliferation and metastasis. (A) The expression levels of miR-647 in GC tissues compared with the expression in adjacent normal tissues in 70 patients. (B) Quantitative reverse transcription real-time polymerase chain reaction (qRT-PCR) of miR-647 expression in GC tissues of patients and adjacent non-tumor tissues. (C) qRT-PCR analysis of miR-647 expression in GC cell lines. (D) Transwell assay of GC cell invasion; ${ }^{*} \mathrm{P}<0.05$. All values represent mean $\pm \mathrm{SE}$.

associated with tumor size, tumor-node-metastasis (TNM) staging and metastasis including lymph node metastasis and distant metastasis that characterize more aggressive tumor phenotypes $(\mathrm{P}<0.05$; Table II).

Since miR-647 was downregulated in GC and associated with tumor growth and metastasis, we speculated that it may play a similar role in GC cells. The expression of miR-647 was also investigated. Consistent with the results in GC patients, the expression of miR-647 in the HGC-27, AGS, SGC-7901 and MGC-803 cell lines was significantly downregulated with a fold-change of $0.58 \pm 0.03,0.57 \pm 0.03,0.32 \pm 0.03$ and $0.10 \pm 0.00$, respectively, compared with that noted in the GES-1 cells $(\mathrm{P}<0.05$; Fig. 1C). We next investigated the invasive ability of the GC cell lines using the Transwell assay. The data demonstrated that the GC cell lines MGC-803 and SGC-7901 displayed a stronger invasive ability with lower levels of miR-647 compared with HGC-27 and AGS cell lines $(\mathrm{P}<0.05$;
Fig. 1D). Overall, these results suggest that miR-647 expression is frequently downregulated in GC, and is correlated with proliferation and metastasis, suggesting that miR-647 acts as a tumor-suppressor in GC development.

miR-647 suppresses GC cell growth. To explore the potential growth-suppressive role of miR-647 in GC, we first established GC cells stably overexpressing miR-647. The miR-647 mimic and LV-GFP were transfected into SGC-7901 or MGC-803 cells that displayed a stronger invasive ability, respectively. The expression of miR-647 in the stably transfected cells was confirmed by qRT-PCR ( $\mathrm{P}<0.05$; Fig. 2A). Cell proliferation assays revealed that miR-647 overexpression significantly reduced the growth rates of the SGC-7901 and MGC-803 cells $(\mathrm{P}<0.05$; Fig. 2B). As shown in Fig. 2C, cell cycle analysis also supported the results, as overexpression of miR-647 was related to G0/G1 phase arrest. Cell counts in the G0/G1 phase 
A

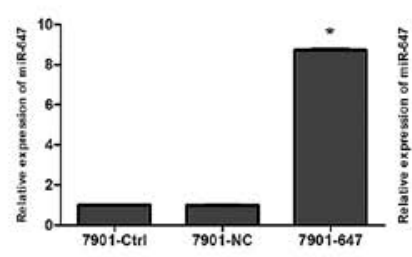

c
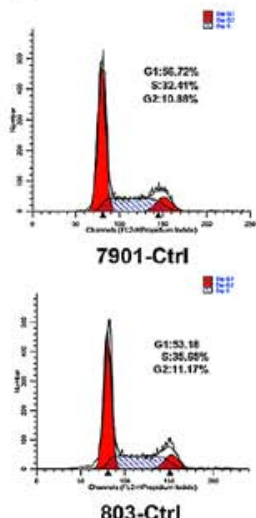

EF:

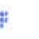

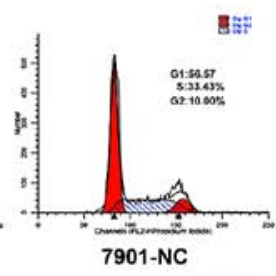

องเม
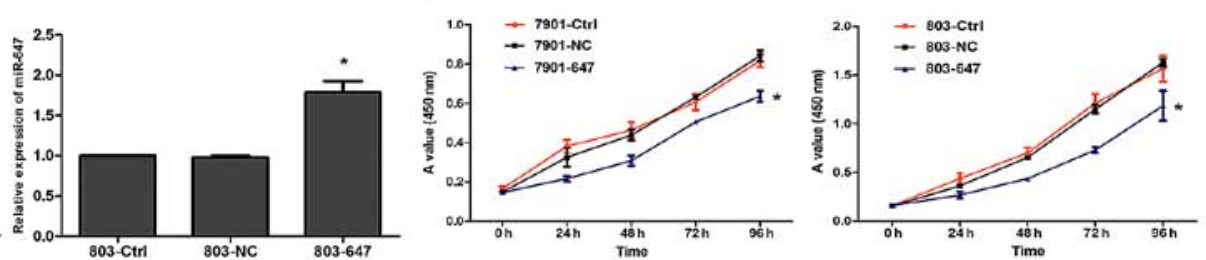

D
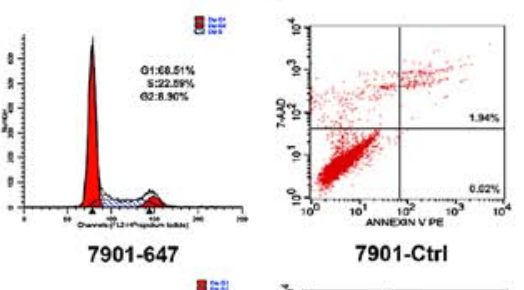

7901-Ctrl
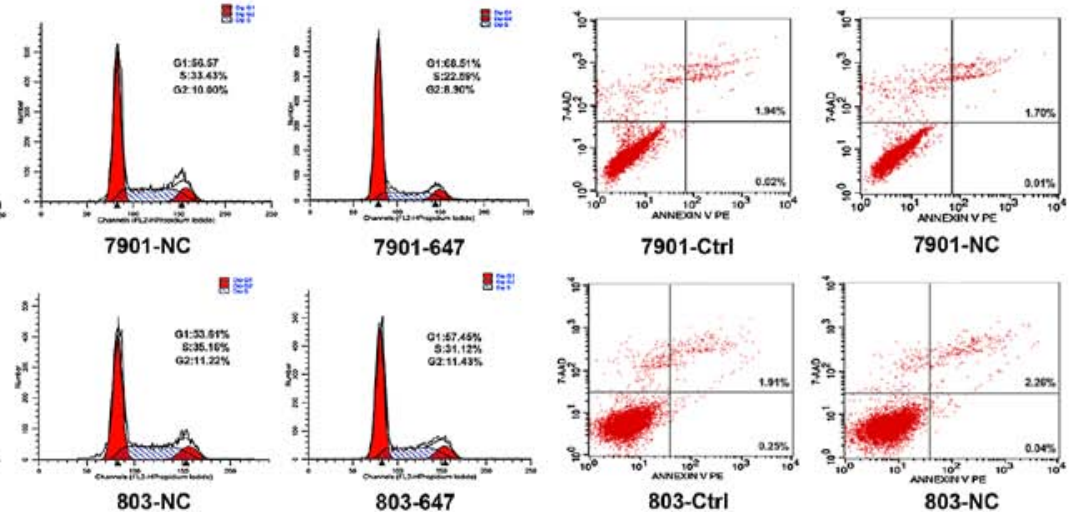

7901-NC
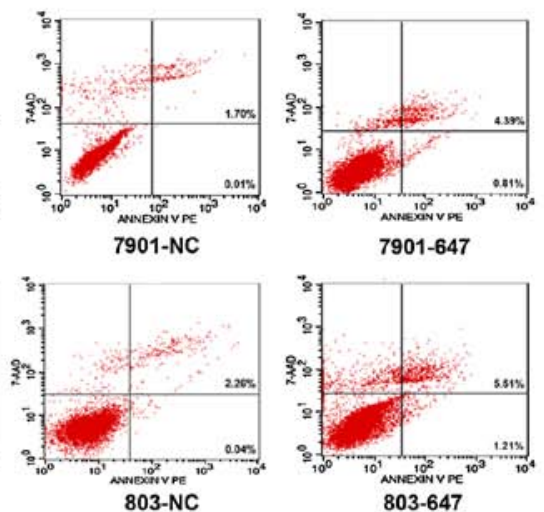

7901-647
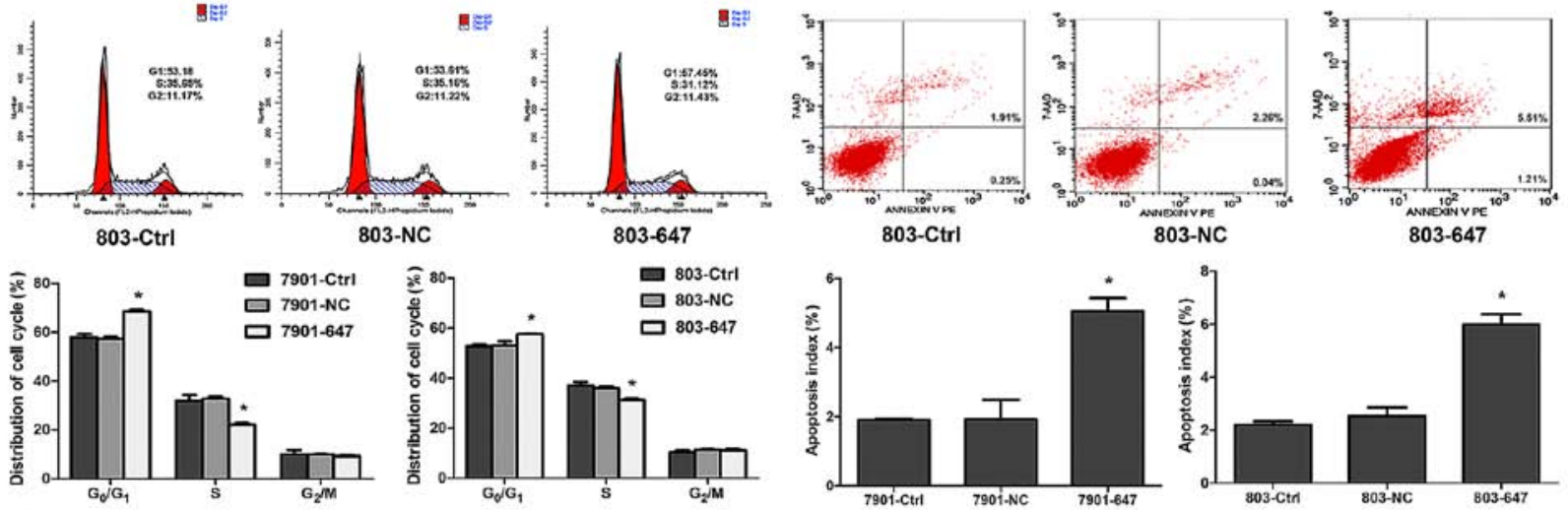

E

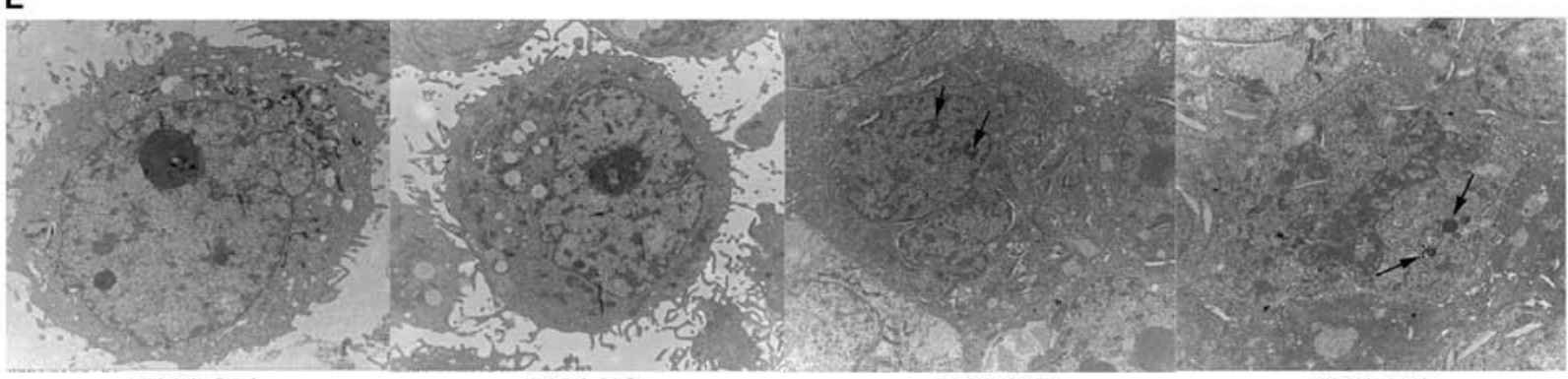

7901-Ctrl

7901-NC

7901-647

7901-647

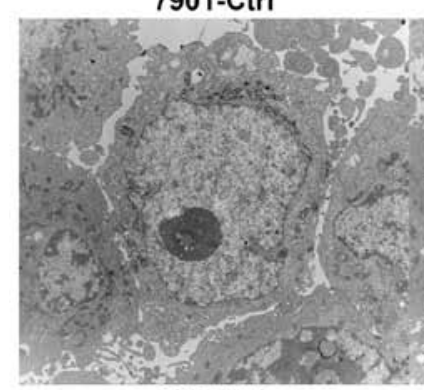

803-Ctrl

803-NC

803-647

Figure 2. miR-647 suppresses GC cell growth in vitro and in vivo. (A) qRT-PCR analysis of the expression of miR-1284 after transfection. (B) The CCK-8 assay was used to measure the effect of miR-647 on GC cell growth. (C) Flow cytometry was used to analyze the cell cycle of GC cells after miR-647 transfection. (D) Flow cytometry was used to analyze apoptosis of GC cells after miR-647 transfection. (E) Images acquired using transmission electron microscopy (magnification $\mathrm{x} 40,000)$. ${ }^{*} \mathrm{P}<0.05$ for the 7901-647 (803-647) group vs. the 7901-NC (803-NC) and 7901-Ctrl (803-Ctrl) groups. All values represent mean \pm SE.

apparently increased while those in the $\mathrm{S}$ phase decreased $(\mathrm{P}<0.05)$. Furthermore, we found that miR-647 increased the basal rate of cells undergoing apoptosis $(\mathrm{P}<0.05$, Fig. 2D). As shown in Fig. 2E, typical features of apoptosis such as formation of apoptotic bodies, chromatin fragmentation or concentration and mitochondrial disappearance or crest fracture were observed in the 7901-647 and 803-647 groups under TEM. Consistent with the results obtained in the in vitro growth assays, miR-647 significantly inhibited the xenograft tumor growth in nude mice $(\mathrm{P}<0.05$, Fig. $2 \mathrm{~F}$ and $\mathrm{G})$. Collectively, these data clearly demonstrate that miR-647 plays a growth-suppressive function in GC. 

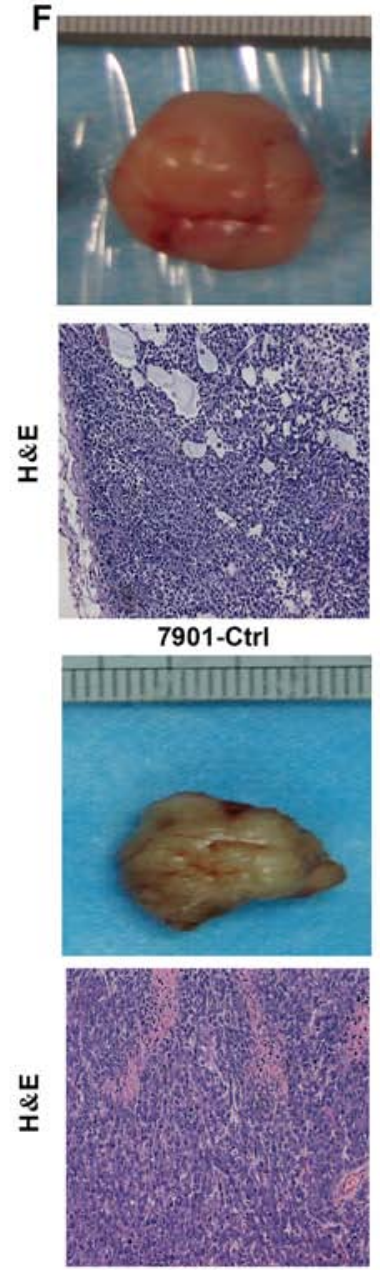

803-Ctrl

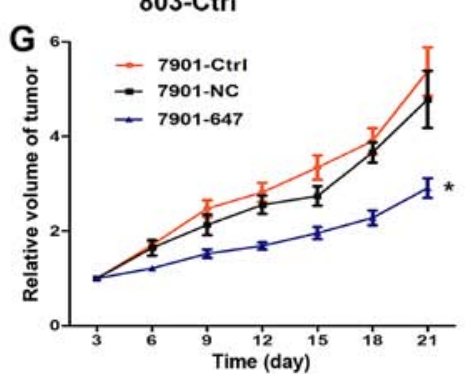

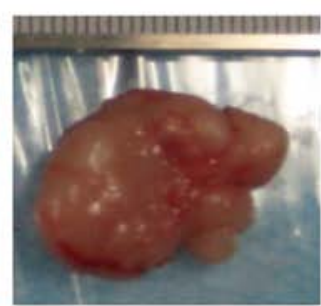
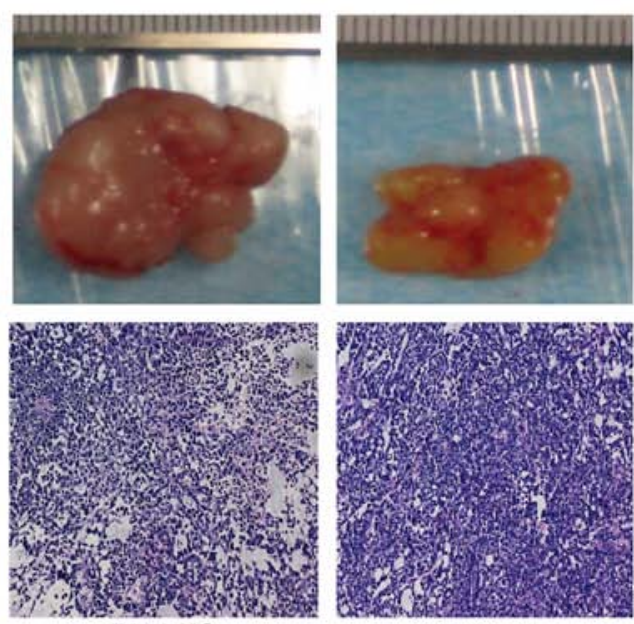

7901-647
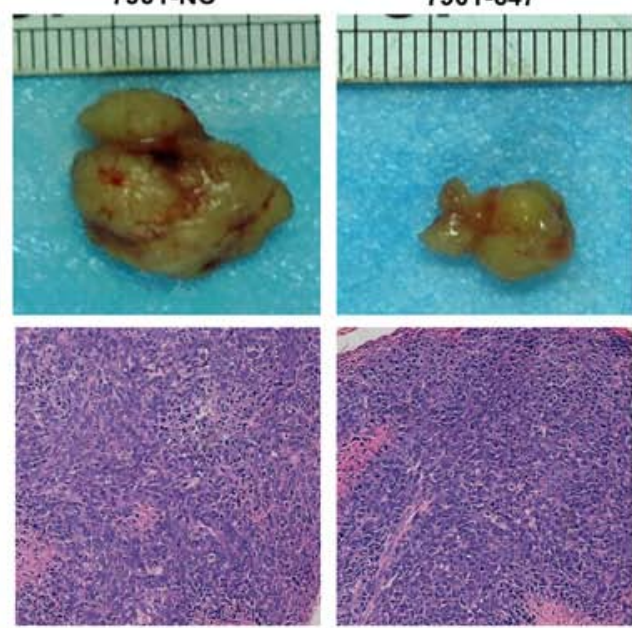

803-NC

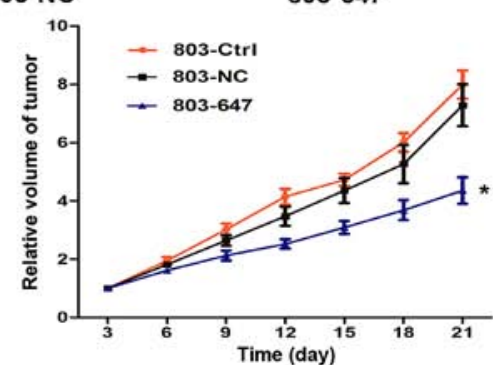

Figure 2. Continued. (F) Xenografts of each group and tumor segments stained with hematoxylin and eosin (magnification, x200). (G) Relative tumor volume (RTV) of each group; ${ }^{*} \mathrm{P}<0.05$ for the 7901-647 (803-647) group vs. the 7901-NC (803-NC) and 7901-Ctrl (803-Ctrl) groups. All values represent mean \pm SE.

miR-647 suppresses GC metastasis. We confirmed that the ectopic expression of miR-647 is closely associated with GC metastasis including lymph node and distant metastasis; that is to say, miR-647 mediates the processes of metastasis in the development of GC. To determine the role of miR-647 in metastasis, the effect of miR-647 overexpression on cell migration and invasion was investigated using wound-healing and Transwell assays with Matrigel. The results demonstrated that overexpression of miR-647 in the SGC7901 and MGC803 cells substantially impaired cell migration $(\mathrm{P}<0.05$; Fig. $3 \mathrm{~A})$. Similarly, miR-647 significantly decreased GC cell invasion in the Matrigel-coated Transwell assay $(\mathrm{P}<0.05$; Fig. 3B). To probe the effect of abnormal expression of miR-647 on tumor metastasis in vivo, controls and miR-647-overexpressing cells were injected into nude mice via the lateral tail vein. As
Table III. Cases of metastasis in lung and liver tissue in a model of metastasis in nude mice for each group $\left({ }^{\mathrm{a}} \mathrm{P}<0.05\right)$.

\begin{tabular}{|c|c|c|c|c|c|c|c|}
\hline \multirow[b]{2}{*}{ Groups } & \multirow[b]{2}{*}{$\begin{array}{c}\text { Total } \\
\text { cases }\end{array}$} & \multicolumn{2}{|c|}{$\begin{array}{c}\text { Lung } \\
\text { metastasis }\end{array}$} & \multirow[b]{2}{*}{$\mathrm{P}$-value } & \multicolumn{2}{|c|}{$\begin{array}{c}\text { Liver } \\
\text { metastasis }\end{array}$} & \multirow[b]{2}{*}{ P-value } \\
\hline & & Cases & $\begin{array}{c}\text { Ratio } \\
(\%)\end{array}$ & & Cases & $\begin{array}{c}\text { Ratio } \\
(\%)\end{array}$ & \\
\hline 7901-Ctrl & 10 & 4 & 40 & 0.451 & 7 & 70 & $0.035^{\mathrm{a}}$ \\
\hline 7901-NC & 10 & 3 & 30 & & 5 & 50 & \\
\hline $7901-647$ & 10 & 1 & 10 & & 1 & 10 & \\
\hline 803-Ctrl & 10 & 4 & 40 & 0.293 & 6 & 60 & 0.061 \\
\hline 803-NC & 10 & 4 & 40 & & 7 & 70 & \\
\hline $803-647$ & 10 & 1 & 10 & & 2 & 20 & \\
\hline
\end{tabular}


A
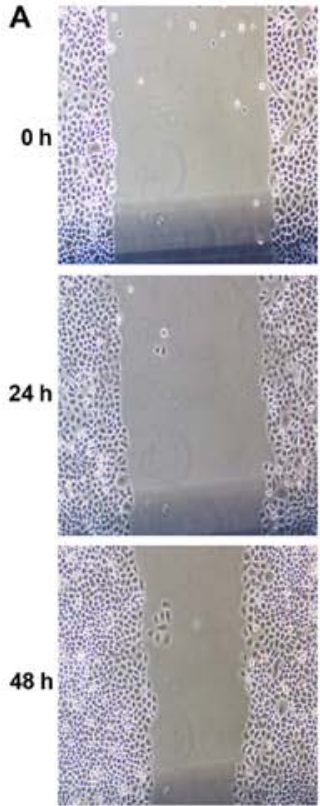

7901-Ctrl
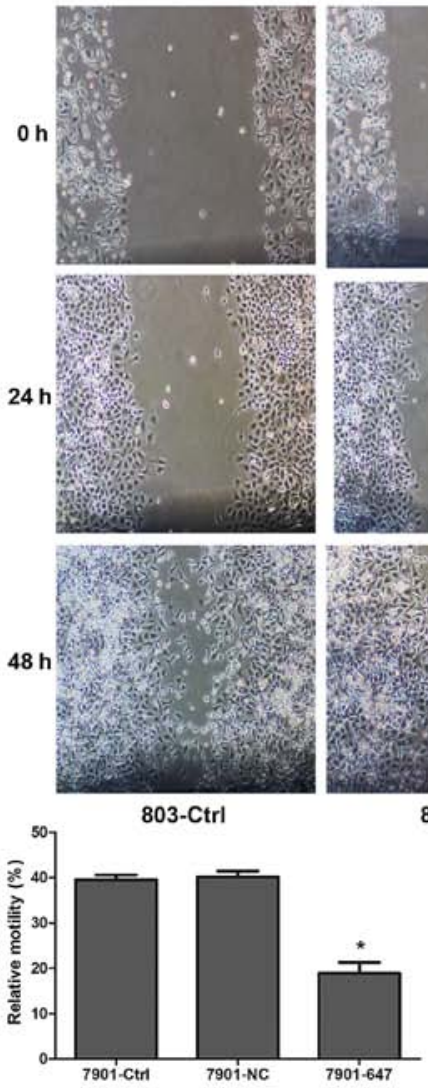
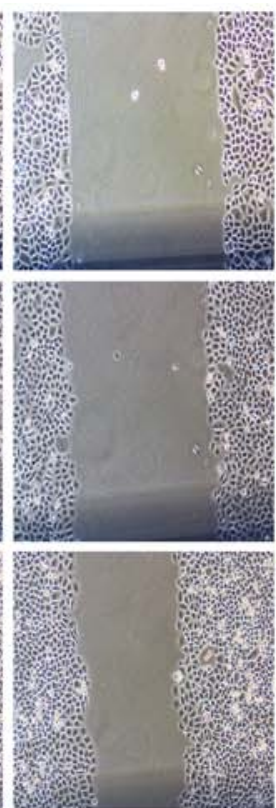

7901-NC
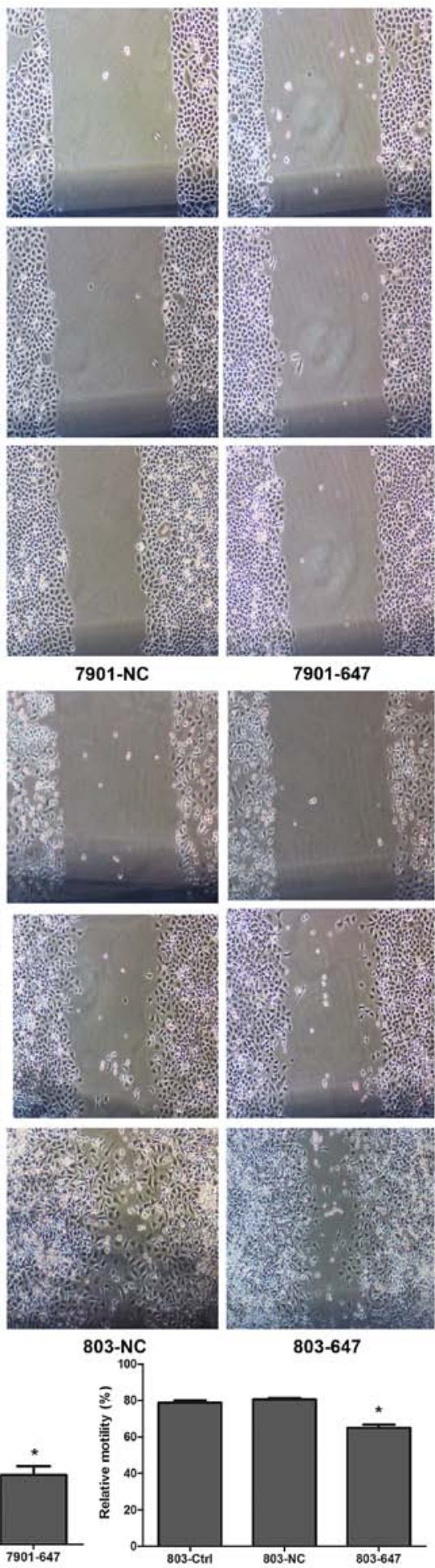

7901-647
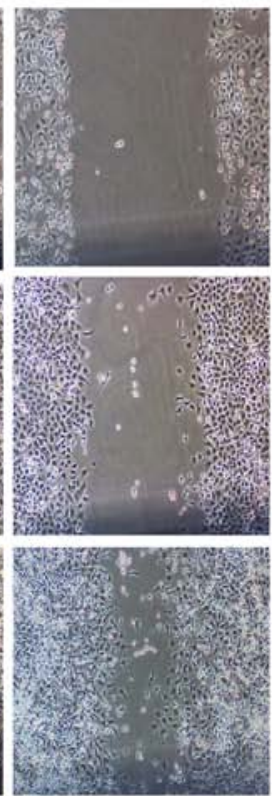

901-Ctr
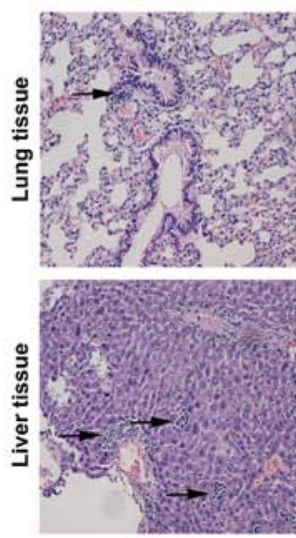

803-Ctrl

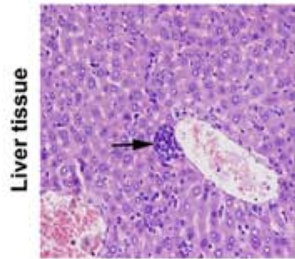

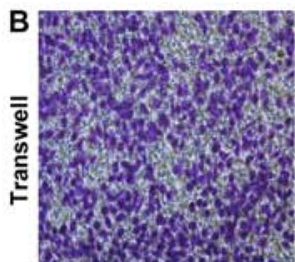

7901-Ctrl

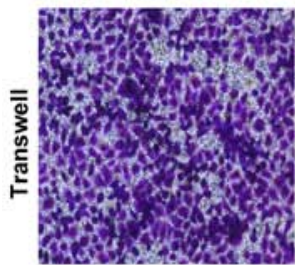

803-Ctrl

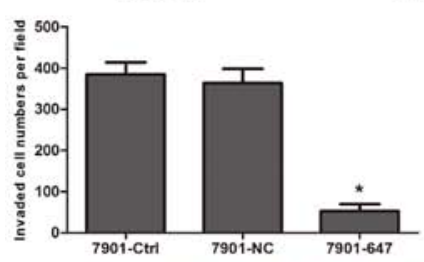

803-NC

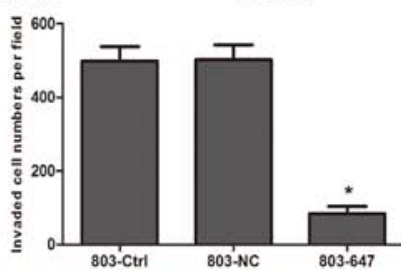

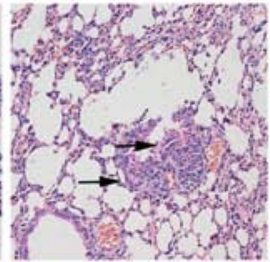
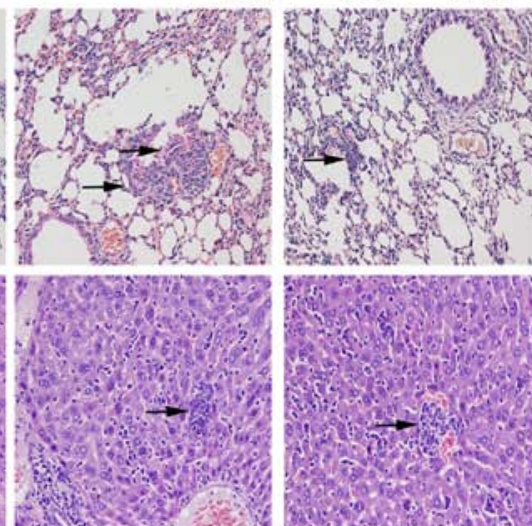

7901-NC
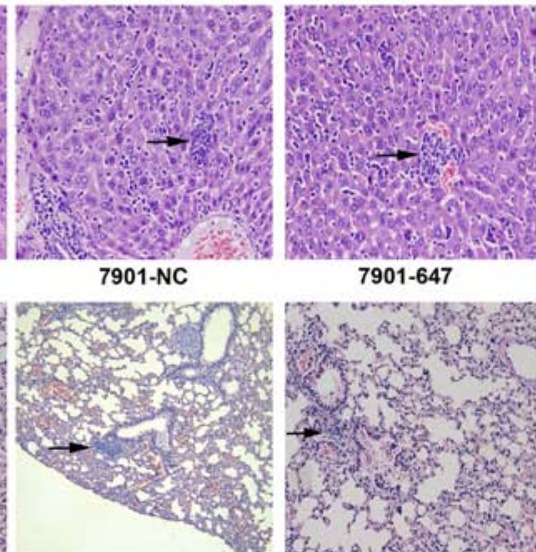

7901-647
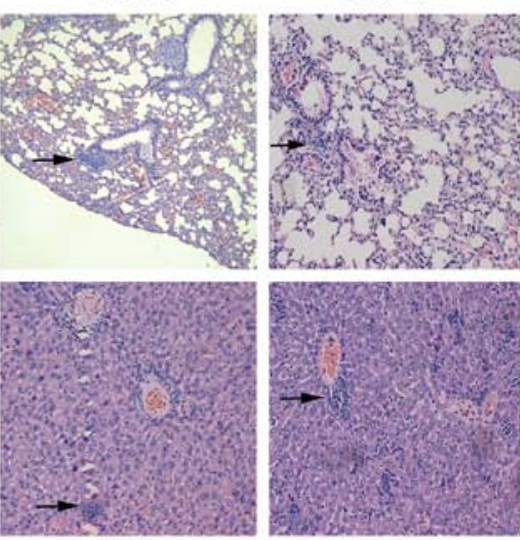

803-NC

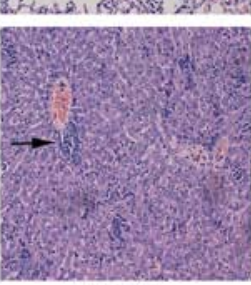

803-647

Figure 3. miR-647 overexpression suppresses GC cell metastasis in vitro and in vivo. (A) Wound-healing assay of GC cell migration potential (magnification, $\mathrm{x} 100)$. The percentage of wound healing is shown in the diagrams. (B) Transwell assay of the invasion of GC cells (magnification, $\mathrm{x} 200$ ). (C) H\&E staining of lung and liver tissues in a metastatic model of nude mice in each group (magnification, $\mathrm{x} 200$ ); ${ }^{*} \mathrm{P}<0.05$ for 7901-647 (803-647) group vs. the 7901-NC (803-NC) and 7901-Ctrl (803-Ctrl) groups. All values represent mean \pm SE.

shown in Fig. 3C and Table III, the result was confirmed by histological staining and statistical analysis, demonstrating that miR-647 overexpression strongly inhibited the ability of GC metastases in the liver. These results clearly indicate that miR-647 suppresses GC migration and invasion.
miR-647 modulates proliferation and metastasis by reducing the expression of ANK2, FAK, MMP2, MMP12, CD44 and SNAIL1. To investigate the molecular mechanisms of miR-647-mediated tumor suppression, potential direct targets for miR-647 were screened by microarray data 


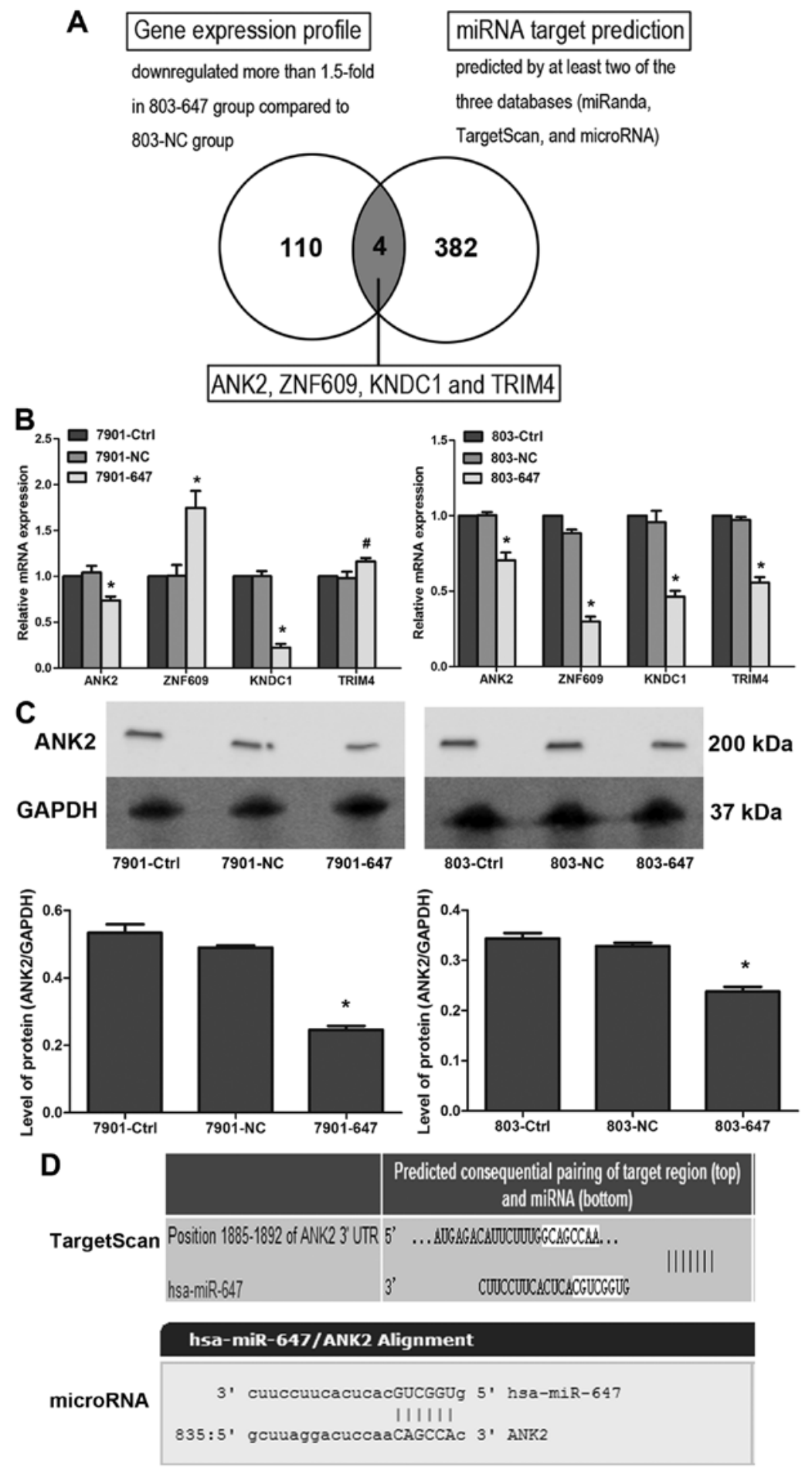

Figure 4. ANK2 is a potential target of miR-647. miR-647 mediates proliferation and metastasis by reducing the expression of ANK2, FAK, MMP2, MMP12, CD44 and SNAIL1. (A) Potential target genes of miR-647 were screened by microarray gene expression profiling combined with bioinformatic target prediction. (B) Quantitative reverse transcription real-time polymerase chain reaction (qRT-PCR) analysis of potential target genes. (C) Western blotting of ANK2 protein. (D) Results of TargetScan and microRNA predicted the target gene of miR-647. ${ }^{*} \mathrm{P}<0.05$ for $7901-647$ (803-647) group vs. the 7901-NC (803-NC) and 7901-Ctrl (803-Ctrl) groups; "P>0.05 for 7901-647 group vs. the 7901-NC and 7901-Ctrl groups. All values are expressed as mean \pm SE.

analysis combined with bioinformatic target prediction. The functional downstream genes for miR-647 were selected via gene expression profiling of 803-647 and 803-NC cells. Of the 31,741 genes analyzed by UinGene Whole Genome DNA array analysis, 113 and 110 were upregulated and downregulated, respectively, which had an expression change $>1.5$-fold in GC cells of the 803-647 group compared with the 803-NC group. Following suppression of most targets by miRNAs, the downregulation of 110 genes in the 803-647 group was analyzed for potential miR-647 direct targets predicted by at least two of the 3 computational target prediction algorithms (miRanda, TargetScan and microRNA). Four potential miR-647 targets, ANK2, ZNF609, KNDC1 and TRIM4 were identified (Fig. 4A). To examine whether or not the 4 potential 

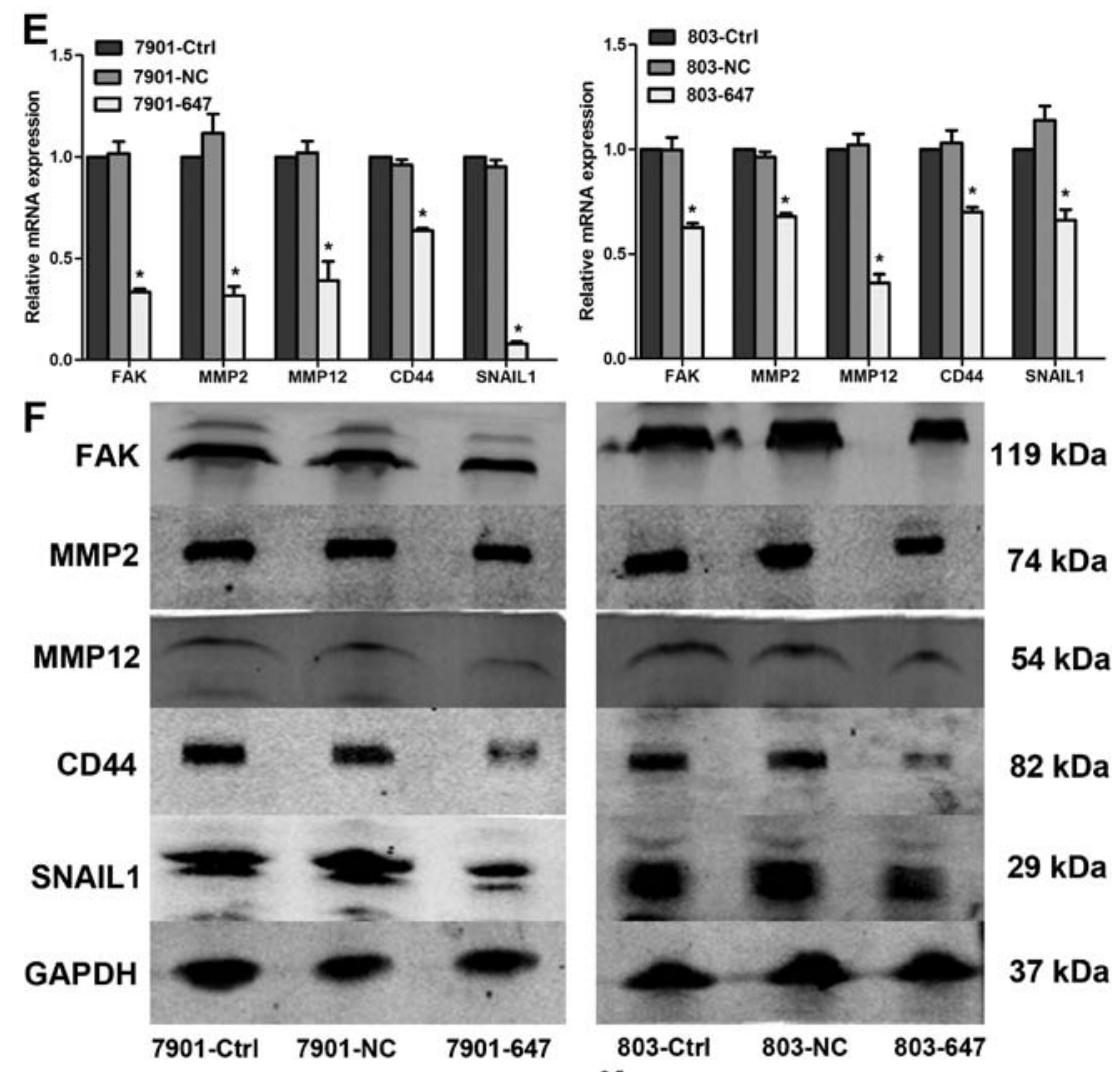

$54 \mathrm{kDa}$

$82 \mathrm{kDa}$

$29 \mathrm{kDa}$

$37 \mathrm{kDa}$
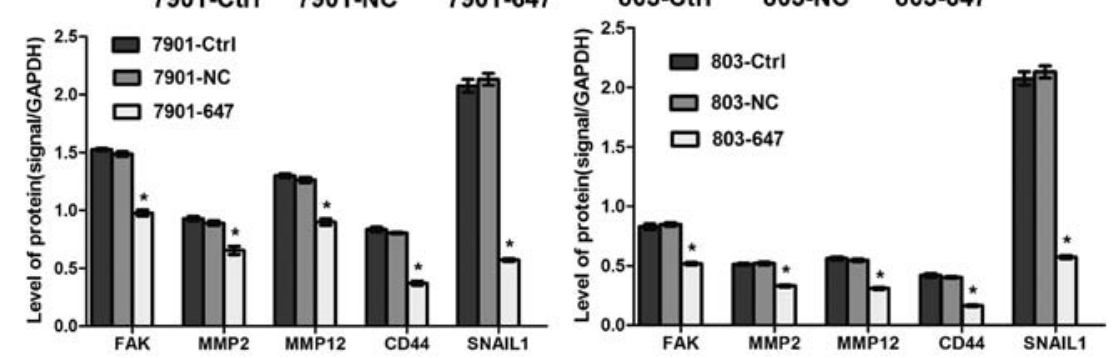

Figure 4. Continued. (E) qRT-PCR of FAK, MMP2, MMP12, CD44 and SNAIL1. (F) Western blotting of FAK, MMP2, MMP12, CD44 and SNAIL1 proteins; ${ }^{*} \mathrm{P}<0.05$ for 7901-647 (803-647) group vs. the 7901-NC (803-NC) and 7901-Ctrl (803-Ctrl) groups; ${ }^{*} \mathrm{P}>0.05$ for $7901-647$ group vs. the 7901-NC and 7901-Ctrl groups. All values are expressed as mean $\pm \mathrm{SE}$.

targets were regulated by miR-647 in GC cell lines, the miR-647 overexpression of SGC7901 and MGC803 cells was analyzed for transcriptional expression of $A N K 2$, ZNF609, KNDC1 and TRIM4 by qRT-PCR. As shown in Fig. 4B, among the 4 potential targets, ANK2 and KNDC1 mRNA expression was suppressed by miR-647 in both cells. Since only ANK2 plays an oncogenic function in tumorigenesis, it was selected for further evaluation as the miR-647 potential target. Furthermore, suppression of ANK2 expression by miR-647 overexpression was confirmed in the SGC7901 and MGC803 cells ( $\mathrm{P}<0.05$; Fig. 4C). As shown in Fig. 4D, ANK2 was a potential target of miR-647 as predicted by TargetScan and miRNA.

To investigate the mechanism by which miR- 647 suppresses GC proliferation and metastasis, we utilized qRT-PCR and western blotting to determine the expression of genes that regulate proliferation and metastasis. Our data demonstrated that the expression of $F A K, M M P 2, M M P 12$, CD44 and SNAIL1 was downregulated after miR-647 overexpression in both SGC7901 and MGC803 cell lines $(\mathrm{P}<0.05$, Fig. 4E and F).

\section{Discussion}

According to the 2012 statistics of the International Agency for Research on Cancer (IARC), gastric cancer is the fifth most common malignancy, and the third leading cause of cancer-related deaths worldwide (14). Recently, tumor invasion, metastatic dissemination, disease relapse, and drug resistance have been identified as classical hallmarks of cancer malignancy, and represent major factors contributing to poor clinical outcomes in cancer patients $(15,16)$. Unfortunately, due to lack of effective diagnostic methods for early stage disease and tumorigenesis in GC, patients are often diagnosed with metastatic disease. Therefore, the discovery of novel molecular biomarkers and targets for diagnosis and treatment of GC is imperative.

Emerging evidence indicates that miRNAs modulate the development of GC. They are closely involved in the regulation of various biological and pathological processes, including tumor growth, cell invasion and tumor metastasis (16,17). Notably, Yang et al (18) reported that miR-647 expression is significantly altered during lymphatic metastasis 
of GC. A recent study also showed that miR-647 is associated with malignant cancer phenotypes and is often used as a biomarker for GC (12). However, miR-647 is a newly identified molecule, with limited data supporting its role in GC. The evidence suggests that miR-647 may function as a tumor suppressor or tumorigenic miRNA. In the present study, we found a significant decrease in the level of miR-647 expression in GC tumors compared with that in the corresponding non-tumor tissues. We further analyzed the correlation of miR-647 expression with clinicopathological characteristics. A robust association between low miR-647 expression and tumor size, lymph node and distant metastases was confirmed in 70 patients with GC. Furthermore, consistent with the results in GC patients, we showed that the expression of miR-647 in SGC-7901, MGC-803, HGC-27 and AGS cells was significantly downregulated compared with that in the GES-1 cells. The SGC-7901 and MGC-803 cells, with lower levels of miR-647, displayed higher invasive ability compared with the HGC-27 and AGS cell lines. These findings suggest that miR-647 plays a tumor-suppressor role in GC and acts as a metastatic biomarker in GC.

To investigate the effect of miR-647 on the proliferation and metastasis of GC cell lines, we re-expressed miR-647 in GC cell lines SGC7901 and MGC803, both of which express a low basal level of miR-647. Re-expression of miR-647 effectively slowed tumor cell growth, inhibited cell cycle entry into the $\mathrm{S}$ phase and increased apoptosis as well as suppressed GC xenograft tumor growth in nude mice. In addition, re-expression of miR-647 decreased tumor cell migration and invasion. Consistently, an experimental animal model of metastasis also confirmed that miR-647 significantly reduced the colonization of metastatic tumors in liver. These data point toward an important role of miR-647, similar to a tumor suppressor, in GC cell growth and metastasis.

To further elucidate the mechanism underlying the role of miR-647, we used three open access programs (miRanda, TargetScan and microRNA) and Microarray Data Analysis to predict targets of miR-647. Among the 4 potential targets (ANK2, ZNF609, KNDC1 and TRIM4), the mRNA expression of KNDC1 and ANK2 was suppressed by miR-647 overexpression in the SGC7901 and MGC803 cells. As ANK2 was previously reported to play an oncogenic role, we focused on the oncogene $A N K 2$ as the potential target. Furthermore, we confirmed that miR-647 overexpression suppressed ANK2 protein expression. Cytoskeletal proteins are positively associated with cell growth and metastasis $(19,20)$. As a member of the cytoskeletal protein family, ANK2 encodes one of the 3 ankyrins: ankyrin-R (ANK1), ankyrin-B (ANK2) and ankyrin-G (ANK3), mediating various integral membrane proteins $(21,22)$. Overexpression of ankyrins has been observed in various cancer cells, including prostate, breast and ovarian cancers (23-25). They play a crucial role in cell growth, membrane transportation, metastasis and migration of cancer cells $(22,23)$. Furthermore, consistent with the present study, a recent study showed that ANK2 was overexpressed in pancreatic tumors and downregulation of ANK2 attenuated the growth and invasion of pancreatic cancers (26). However, there is no sufficient evidence to support the role of ANK2 in GC. Our findings suggest that miR-647 inhibits proliferation and metastasis in GC by downregulating ANK2. To the best of our knowledge, the present study provides initial evidence supporting the role of miR-647 in the downregulation of ANK2 in GC.

We also demonstrated that FAK, MMP2, MMP12, CD44 and SNAIL1 are downstream effectors of miR-647-ANK2 based on interference studies demonstrating that FAK, MMP2, MMP12, CD44 and SNAIL1 expressions were decreased by miR-647-ANK2 expression. The ANK2/FAK/MMP2/ MMP12 and ANK2/CD44/SNAIL1 signaling pathways represent a rare integrated network mediating the proliferation and metastasis of GC. Our results were consistent with previous data indicating that ANK2 may affect signal transduction mediated by FAK activity. FAK plays a pivotal role in the secretion of matrix metalloproteinases (MMPs) $(26,27)$. As a potential prognostic indicator, decreased focal adhesion kinase (FAK) expression mediates the inhibition of cell proliferation and limits the induction of metastasis in GC $(28,29)$. Additionally, MMP2 and MMP12 belong to the group of MMPs, which are known for their key role in tumor metastasis and invasiveness $(30,31)$. Recent studies have shown that inhibition of MMP2 and MMP12 suppresses the invasion of gastric and lung cancers $(32,33)$.

Ankyrins (including ANK1, ANK2 and ANK3) link various transmembrane proteins to actin network, and bind to CD44 domains. CD44, an important cell membrane receptor, which consists of a conserved intracellular ankyrin-binding region, links the external environment to the cytoskeleton. It mediates a variety of cellular behaviors including mitogenesis, adhesion and migration and was found to interact with growth and metastasis in malignant cells (34-36). Inhibition of CD44 was found to decrease the expression of SNAIL1 and the potential for invasion in pancreatic cancer cells $(37,38)$. Recent studies have shown that epithelial-to-mesenchymal transition (EMT) is associated with the acquisition of metastasis in GC cells (39). The transcription factor SNAIL1 represses epithelial factors such as E-cadherin, and its expression is sufficient for EMT (40). Consequently, inhibition of SNAIL1 expression prevents EMT resulting in suppression of cell proliferation and metastasis (41).

In conclusion, in the present study, miR-647 expression was found to decrease the expression of ANK2/FAK/MMP2/ MMP12 and ANK2/CD44/SNAIL1 signaling pathways, directly or indirectly, resulting in inhibition of the proliferation and metastasis of GC cells in vitro and in vivo. For the first time, the present study demonstrated a relationship between miR-647 and ANK2, indicating the potential role of miR-647 in the regulation of GC development. Furthermore, it underscores the role of miR-647 as a potential biomarker in GC and further investigation should be carried out to confirm that targeting this gene may aid in the diagnosis and treatment of gastric carcinoma.

\section{Acknowledgements}

The present study was supported by grants from the National Natural Science Foundation of China (nos. 81660511, 30860273 and 81060201), the Natural Science Foundation of Guangxi (no. 2015GXNSFDA227001), the Key Health Science Foundation of Guangxi (no. 14124004-1-9), and the Innovation Project of Guangxi Graduate Education. 


\section{References}

1. Hamashima C: Current issues and future perspectives of gastric cancer screening. World J Gastroenterol 20: 13767-13774, 2014.

2. Shmulevich I: Large-scale molecular characterization and analysis of gastric cancer. Chin J Cancer 33: 369-370, 2014.

3. Piazuelo MB and Correa P: Gastric cáncer: Overview. Colomb Med 44: 192-201, 2013.

4. Ambros V: The functions of animal microRNAs. Nature 431: 350-355, 2004

5. Alizadeh S, Azizi SG, Soleimani M, Farshi Y and Kashani Khatib Z: The role of microRNAs in myeloproliferative neoplasia. Int J Hematol Oncol Stem Cell Res 10: 172-185, 2016.

6. Zhao Y and Srivastava D: A developmental view of microRNA function. Trends Biochem Sci 32: 189-197, 2007.

7. Bushati $\mathrm{N}$ and Cohen SM: microRNA functions. Annu Rev Cell Dev Biol 23: 175-205, 2007.

8. Esquela-Kerscher A and Slack FJ: Oncomirs - microRNAs with a role in cancer. Nat Rev Cancer 6: 259-269, 2006.

9. Hata A and Lieberman J: Dysregulation of microRNA biogenesis and gene silencing in cancer. Sci Signal 8: re3, 2015

10. Zheng H, Zhang F, Lin X, Huang C, Zhang Y, Li Y, Lin J, Chen W and Lin X: MicroRNA-1225-5p inhibits proliferation and metastasis of gastric carcinoma through repressing insulin receptor substrate- 1 and activation of $\beta$-catenin signaling. Oncotarget 7 : 4647-4663, 2016.

11. Zuo QF, Zhang R, Li BS, Zhao YL, Zhuang Y, Yu T, Gong L, Li S, Xiao B and Zou QM: MicroRNA-141 inhibits tumor growth and metastasis in gastric cancer by directly targeting transcriptional co-activator with PDZ-binding motif, TAZ. Cell Death Dis 6: e1623, 2015.

12. Rawlings-Goss RA, Campbell MC and Tishkoff SA: Global population-specific variation in miRNA associated with cancer risk and clinical biomarkers. BMC Med Genomics 7: 53, 2014

13. Kim YW, Kim EY, Jeon D, Liu JL, Kim HS, Choi JW and Ahn WS: Differential microRNA expression signatures and cell type-specific association with Taxol resistance in ovarian cancer cells. Drug Des Devel Ther 8: 293-314, 2014.

14. Yuan DD, Zhu ZX, Zhang X and Liu J: Targeted therapy for gastric cancer: Current status and future directions (Review) Oncol Rep 35: 1245-1254, 2016.

15. Nishida T, Egashira Y, Akutagawa H, Fujii M, Uchiyama K, Shibayama $\mathrm{Y}$ and Hirose $\mathrm{Y}$ : Predictors of lymph node metastasis in T1 colorectal carcinoma: An immunophenotypic analysis of 265 patients. Dis Colon Rectum 57: 905-915, 2014

16. Díaz-López A, Moreno-Bueno G and Cano A: Role of microRNA in epithelial to mesenchymal transition and metastasis and clinical perspectives. Cancer Manag Res 6: 205-216, 2014.

17. Santos JI, Teixeira AL, Dias F, Gomes M, Nogueira A, Assis J and Medeiros R: Restoring TGF $\beta 1$ pathway-related microRNAs: Possible impact in metastatic prostate cancer development. Tumour Biol 35: 6245-6253, 2014.

18. Yang B, Jing C, Wang J, Guo X, Chen Y, Xu R, Peng L, Liu J and Li L: Identification of microRNAs associated with lymphangiogenesis in human gastric cancer. Clin Transl Oncol 16: 374-379, 2014.

19. Zhu L, Ito T, Nakahara T, Nagae K, Fuyuno Y, Nakao M, Akahoshi M, Nakagawa R, Tu Y, Uchi H, et al: Upregulation of S100P, receptor for advanced glycation end products and ezrin in malignant melanoma. J Dermatol 40: 973-979, 2013

20. Fujimoto D, Hirono Y, Goi T, Katayama K, Matsukawa S and Yamaguchi A: The activation of proteinase-activated receptor-1 (PAR1) promotes gastric cancer cell alteration of cellular morphology related to cell motility and invasion. Int J Oncol 42: $565-573,2013$

21. Lambert $S$ and Bennett V: Postmitotic expression of ankyrinR and beta R-spectrin in discrete neuronal populations of the rat brain. J Neurosci 13: 3725-3735, 1993.

22. De Matteis MA and Morrow JS: The role of ankyrin and spectrin in membrane transport and domain formation. Curr Opin Cell Biol 10: 542-549, 1998
23. Zhu D and Bourguignon LY: Interaction between CD44 and the repeat domain of ankyrin promotes hyaluronic acid-mediated ovarian tumor cell migration. J Cell Physiol 183: 182-195, 2000.

24. Bourguignon LY, Zhu H, Shao L and Chen YW: Ankyrin-Tiam1 interaction promotes Racl signaling and metastatic breast tumor cell invasion and migration. J Cell Biol 150: 177-191, 2000.

25. Zhu D and Bourguignon LY: The ankyrin-binding domain of CD44s is involved in regulating hyaluronic acid-mediated functions and prostate tumor cell transformation. Cell Motil Cytoskeleton 39: 209-222, 1998.

26. Chen Y, Löhr M and Jesnowski R: Inhibition of ankyrin-B expression reduces growth and invasion of human pancreatic ductal adenocarcinoma. Pancreatology 10: 586-596, 2010.

27. Sein TT, Thant AA, Hiraiwa Y, Amin AR, Sohara Y, Liu Y, Matsuda S, Yamamoto T and Hamaguchi M: A role for FAK in the Concanavalin A-dependent secretion of matrix metalloproteinase-2 and -9. Oncogene 19: 5539-5542, 2000.

28. Pei YF, Tao R, Li JF, Su LP, Yu BQ, Wu XY, Yan M, Gu QL, Zhu ZG and Liu BY: TET1 inhibits gastric cancer growth and metastasis by PTEN demethylation and re-expression. Oncotarget 7: 31322-31335, 2016.

29. You T, Gao W, Wei J, Jin X, Zhao Z, Wang C and Li Y: Overexpression of LIMK1 promotes tumor growth and metastasis in gastric cancer. Biomed Pharmacother 69: 96-101, 2015.

30. Wu L, Tanimoto A, Murata Y, Sasaguri T, Fan J, Sasaguri Y and Watanabe T: Matrix metalloproteinase-12 gene expression in human vascular smooth muscle cells. Genes Cells 8: 225-234, 2003.

31. Xie S, Issa R, Sukkar MB, Oltmanns U, Bhavsar PK, Papi A, Caramori G, Adcock I and Chung KF: Induction and regulation of matrix metalloproteinase-12 in human airway smooth muscle cells. Respir Res 6: 148, 2005.

32. Wang B, Xu YF, He BS, Pan YQ, Zhang LR, Zhu C, Qu LL and Wang SK: RNAi-mediated silencing of CD147 inhibits tumor cell proliferation, invasion and increases chemosensitivity to cisplatin in SGC7901 cells in vitro. J Exp Clin Cancer Res 29: 61, 2010.

33. Lv FZ, Wang JL, Wu Y, Chen HF and Shen XY: Knockdown of MMP12 inhibits the growth and invasion of lung adenocarcinoma cells. Int J Immunopathol Pharmacol 28: 77-84, 2015.

34. Turley EA, Noble PW and Bourguignon LY: Signaling properties of hyaluronan receptors. J Biol Chem 277: 4589-4592, 2002.

35. Bourguignon LY, Singleton PA, Diedrich F, Stern R and Gilad E: CD44 interaction with $\mathrm{Na}^{+}-\mathrm{H}^{+}$exchanger (NHE1) creates acidic microenvironments leading to hyaluronidase-2 and cathepsin $\mathrm{B}$ activation and breast tumor cell invasion. J Biol Chem 279: 26991-27007, 2004.

36. Bourguignon LY, Zhu H, Zhou B, Diedrich F, Singleton PA and Hung MC: Hyaluronan promotes CD44v3-Vav2 interaction with Grb2-p185 ${ }^{\mathrm{HER} 2}$ and induces Rac1 and Ras signaling during ovarian tumor cell migration and growth. J Biol Chem 276: 48679-48692, 2001.

37. Lokeshwar VB, Fregien N and Bourguignon LY: Ankyrin-binding domain of CD44(GP85) is required for the expression of hyaluronic acid-mediated adhesion function. J Cell Biol 126 1099-1109, 1994.

38. Jiang W, Zhang Y, Kane KT, Collins MA, Simeone DM, di Magliano MP and Nguyen KT: CD44 regulates pancreatic cancer invasion through MT1-MMP. Mol Cancer Res 13: 9-15, 2015.

39. Zhao J, Yang C, Guo S and Wu Y: GM130 regulates epithelial-tomesenchymal transition and invasion of gastric cancer cells via snail. Int J Clin Exp Pathol 8: 10784-10791, 2015.

40. Cano A, Pérez-Moreno MA, Rodrigo I, Locascio A, Blanco MJ, del Barrio MG, Portillo F and Nieto MA: The transcription factor snail controls epithelial-mesenchymal transitions by repressing E-cadherin expression. Nat Cell Biol 2: 76-83, 2000.

41. Kudo-Saito C, Shirako H, Takeuchi T and Kawakami Y: Cancer metastasis is accelerated through immunosuppression during Snail-induced EMT of cancer cells. Cancer Cell 15: 195-206, 2009. 